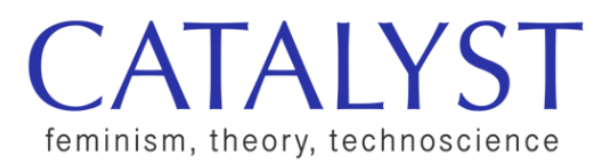

\title{
Book Review | Matters of Care: Speculative Ethics in More Than Human Worlds, by María Puig de la Bellacasa (University of Minnesota Press, 2017)
}

Sophia Chao

University of Sydney

sophie.chao@sydney.edu.au

Drawing from over forty years of empirical and theoretical work in science and technology studies (STS), feminist studies, ethical theory, and environmental humanities, María Puig de la Bellacasa's Matters of Care offers a speculative exploration of the significance of care for thinking, knowing, and living in more than human worlds (p. 1). Puig de la Bellacasa demonstrates that expanding the scope of worlds beyond the human both extends and challenges notions of care that have all too often been tethered to idealizing, moralizing, gendered, hegemonic, and anthropocentric values, practices, and institutions. She highlights the centrality of care-both given and received - to human and other beings, while also attending critically to care's ambivalent and situated meaning, enactment, and consequences. Far from an innocent venture, care reveals itself decidedly non-innocent, non-symmetrical, and multi-lateral (p. 221). These premises motivate Puig de la Bellacasa to approach care both as a modality and object of speculation, which in turn shapes the book's central argument that "an ethical reorganization of human-nonhuman relations is vital, but what this means in terms of caring obligations that could enact nonexploitative forms of togetherness cannot be imagined once for all" (p. 24).

The book is structured as five chapters divided into two parts. Part I engages with

Chao, Sophia (2020). Review of Matters of Care: Speculative Ethics in More Than Human Worlds, by María Puig de la Bellacasa (University of Minnesota Press, 2017). Catalyst: Feminism, Theory,

Technoscience, 6(2), pp. 1-5.

http://www.catalystjournal.org | ISSN: 2380-3312

(C) Sophia Chao, 2020 | Licensed to the Catalyst Project under a Creative Commons Attribution Non-Commercial No Derivatives license 
feminist and STS theory to examine the politics of thinking and knowing in the more than human worlds of technoscience. Articulated around Bruno Latour's notion of "matters of concern," Chapter 1 approaches care as an oppositional practice that at once troubles the democratic assembly of articulate concerns, foregrounds exclusions and suffering within this assembly, and fosters alternative, possible affective involvements with the more than becomings of science and technology. Engaging a feminist vision of care in the politics of things, Puig de la Bellacasa suggests, both enables and problematizes the possibility of translating ethico-political caring into ways of thinking with nonhumans (pp. 31-39).

Drawing from Donna Haraway's notion of situated knowledges, Chapter 2 explores how to "think with care" through a series of three concrete moves (pp. 78-84). "Thinking-with" entails acknowledging the intra-actions and relationality of each person, being, and thing with each other, in ways that allow us to move beyond fixed and bounded categories and wholes. "Dissenting-within" enables a non-idealized vision of care and knowledge-making-one that does not preclude conflict, difference, and incommensurability. "Thinking-for" draws attention to the risks of fetishization and appropriation entailed in attempting to think and act from the perspective and on behalf of, nonhumans.

The notion of non-idealized care returns in Chapter 3, which explores knowledge politics by reading caring, thinking, and knowing as touch. Touch or haptics, Puig de la Bellacasa suggests, enables us to reframe care as a force distributed across a multiplicity of agencies and materials. It brings to light the ambivalences of caring knowledge as an intensification of involvement and proximity, and its distributed consequences for human and nonhuman parties. Touch's unique quality of reversibility-namely, the fact that we cannot touch without being touched-also puts the question of reciprocity, both achieved and unrequited, at the heart of thinking and living with care (pp. 114-20).

Shifting away from the predominantly theoretical approach of the first half of the book, Part II draws from Puig de la Bellacasa's empirical research on permaculture practices and human-soil relations to examine care in relational webs of more than human living ecologies. Chapter 4 explores how the ecological movement known as permaculture displaces traditional understandings of the ethical expounded in ethical theory, postconventional and poststructuralist ethical approaches, and biopolitics. Specifically, ethical obligations once defined in relation to anthropocentric moral principles transform into obligations that are embedded in the vitality and potentiality of material forces themselves. Puig de la 
Bellacasa offers the concept of "alterbiopolitics" to describe the ethics of collective empowerment that permaculture invites. This ethics recognizes how nonhuman entities alternately enable or constrain the continuation of bios as a more than human community, and "puts caring at the heart of the search of everyday struggles for hopeful flourishing of all beings" (pp. 22, 130).

The fifth and final chapter examines divergent yet interconnected ways of caring for the soil through the lens of "temporalities of care." Drawing from scientific research and other domains of soil practice, Puig de la Bellacasa explores how the pace required by ecological relations with soils sits at odds with accelerated, future-oriented responses characteristic of the pace of technoscientific innovation (pp. 195-203). Making time for care time, Puig de la Bellacasa suggests, serves to disrupt the anthropocentric, technoscientific, productionist, and future-driven nature and telos of these temporalities, paving the way for alternative practical, ethical, and affective ecologies of care.

Matters of Care grapples with the concomitant challenges of decentering human agency as the starting point of care, keeping specific ethical obligations, and thickening the meanings of care within the situatedness of more than human relations (pp. 217-18). Puig de la Bellacasa navigates these difficult terrains by drawing from established bodies of literature and from her own personal trajectories of thinking and feeling, making for a work that is at once intellectually rich and richly biographical. She examines with great nuance the potential pitfalls of framing care as a moral imperative and approaches care instead as openended, messy, and situated in both form and effect. Rather than seeking to define a normative framework of what counts as good, necessary, or warranted care ( $p$. 7), Puig de la Bellacasa attends critically to the tensions at play in reconciling care as labor/work, affect/affections, and ethics/politics (p. 5).

Central to Puig de la Bellacasa's analysis is the method of "displacement." Displacement entails exploring care in issues and debates in which it has not frequently been addressed-in this case, technoscience and naturecultures. Displacement also involves examining how divergent modes of valuing care coexist and co-make each other within uneven hierarchies of power and agency (p. 12). Thinking about care through and as displacement in turn highlights care's potential to subvert the status quo, to destabilize the moral strictures of ethical questioning, and to nurture a recognition that no definitive critique or "outside" point of view on care is either possible or indeed desirable (p. 11). The notion of "displacement" deployed by Puig de la Bellacasa offers fruitful avenues to rethink 
other concepts within and beyond the remit of care-violence, relationality, entanglement, and more.

While most of the content of book has already been previously published, the book is nonetheless helpful in synthesizing Puig de la Bellacasa's work into one, conceptual whole. Chapters 1 to 3 are self-avowedly theoretical, and sometimes difficult to follow because of their high level of abstraction. Chapters 4 and 5 offer more empirically grounded materials and arguments that are not only easier to grasp but also more in line with the notion of care itself as, in Puig de la Bellacasa's terms, "unthinkable in abstract terms and outside of its situatedness" (p. 6). As is often the case with more than human theorizing, the book could have usefully engaged in more depth with the politics of care at play in the context of race, sexuality, colonialism, and their differential and hierarchized classifications of what or who counts as human, subhuman, or nonhuman. Useful works to read in conjunction with Matters of Care in this regard might include Claire Kim's Dangerous Crossings (2015), which explores how race and species operate as conjoined and mutually constitutive logics; Arturo Escobar's Pluriversal Politics (2019) on care and the politics of the possible in social activism and more than human worlds; Eva Giraud's What Comes after Entanglement? (2019) on hierarchies of care and responsibility; and Hi'ilei Hobart and Tamara Kneese's special issue in Social Text (2020) on "radical care" in feminist, queer, and Black activism.

The Coda to the book leaves the reader with some of the important and troubling questions to ask of care. For instance, is associating care with ethicality a form of anthropocentrism? Is the notion that other than humans participate in "taking care" of the more than human world merely a wishful and anthropomorphic metaphor? Can there be reciprocity in affective care, however uneven, with other than human beings? (p. 218). While Puig de la Bellacasa leaves these questions open for further investigation, she speaks with conviction to the need for "speculative thinking," "fabulation," "multispecies imaginaries," and "multiple stories," and "ethical imagination" to resist the paralyzing politics of despair that can so often haunt discussions around care (pp. 219-20). Such methods may not necessarily reconfigure practices of care in the immediate present. But they are nonetheless critical if care and its subjects/objects are to resist domination by hegemonic, unilinear, and productionist narratives (p. 221).

\section{References}

Escobar, A. (2019). Pluriversal politics: The real and the possible. Duke University Press. 
Giraud, E. H. (2019). What comes after entanglement? Activism, anthropocentrism, and an ethics of exclusion. Duke University Press.

Hobart, Hi'ilei J. K., \& Kneese, T., (Eds.) (2020). Radical care [Special issue] Social

Text, 38 (1). https://read.dukeupress.edu/social-text/issue/38/1\%20(142)

Kim, C. J. (2015). Dangerous crossings: Race, species, and nature in a multicultural age. Cambridge University Press.

\section{Author Bio}

Sophie Chao is a postdoctoral research associate at the University of Sydney's School of Philosophical and Historical Inquiry. Her research examines the intersections of capitalism, ecology, health, and Indigeneity in Indonesia. 